
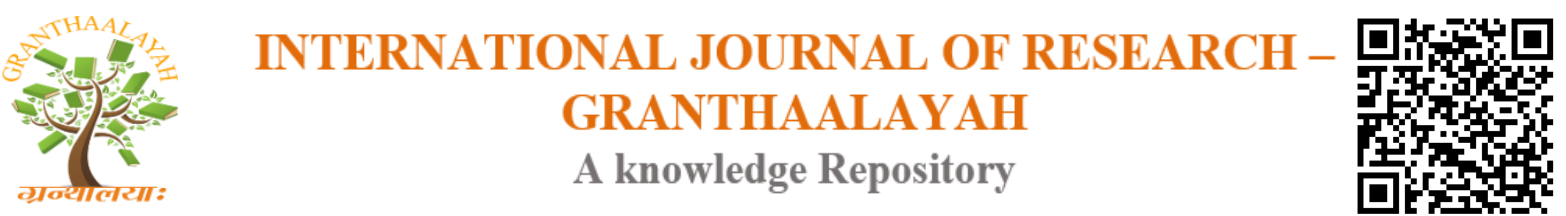

Science

\title{
HEAT TRANSFER ENHANCEMENT USING CIRCUMFERENTIAL FINNED TWISTED TAPE HEAT EXCHANGER
}

\author{
Sudha Brahma Naidu P. ${ }^{* 1}$, P. S. Kishore ${ }^{2}$ \\ ${ }^{* 1,2}$ Department of Mechanical Engineering, College of Engineering (A) Andhra University, \\ Visakhapatnam, Andhra Pradesh, India
}

\begin{abstract}
The most desirable feature in any thermal equipment is the enhancement of heat transfer. Heat transfer is basically a slow process and is enhanced by adopting passive or active methods of enhancement. In passive enhancement methods, heat transfer is increased without demanding any external power source; while in active method, enhancement in heat transfer demand external power. In this work, a passive enhancement method is proposed and tested to check the extent of heat transfer enhancement noticed. A tube in shell heat exchanger is designed with circumferential fins attached along the length of tube and a spiral insert running inside the tube. One fluid is made to flow inside the tube under the influence of twisted tape and the shell side fluid is running around the tube continuously provoked by fins. Therefore, the hot and cold fluids were estimated to exchange more heat because of thorough mixing initiated in their flow paths. In this work, analysis was made in CFD package by creating a model that simulates experimentations observed in the literature. The results of experiments and results of CFD analysis were compared. Noticing the agreement between the results, the CFD model is given enhancements like circumferential fins and twisted tape to check the enhancement in heat transfer. The velocity and temperature contours were observed at various flow conditions (Reynolds numbers). Based on results of analysis, thermal performance factor is also estimated to check the increment in heat transfer with reference to hydraulic (or flow) parameters.
\end{abstract}

Keywords: Augmentation; Reynolds Number; Nusselt Number; Shear Stress; Friction Factor; Thermal Performance Factor.

Cite This Article: Sudha Brahma Naidu P., and P. S. Kishore (2017). "HEAT TRANSFER ENHANCEMENT USING CIRCUMFERENTIAL FINNED TWISTED TAPE HEAT EXCHANGER." International Journal of Research - Granthaalayah, 5(9), 152-163. https://doi.org/10.29121/granthaalayah.v5.i9.2017.2225.

\section{Introduction}

Heat exchangers are used in different processes ranging from conversion, utilization \& recovery of thermal energy in various industrial, commercial \& domestic applications. Some common examples include steam generation \& condensation in power \& cogeneration plants; sensible 
heating \& cooling in thermal processing of chemical, pharmaceutical \& agricultural products; fluid heating in manufacturing \& waste heat recovery etc. Increase in Heat exchanger's performance can lead to more economical design of heat exchanger which can help to make energy, material \& cost savings related to a heat exchange process. The need to increase the thermal performance of heat exchangers, thereby effecting energy, material $\&$ cost savings have led to development \& use of many techniques termed as Heat transfer Augmentation. These techniques are also referred as Heat transfer Enhancement or Intensification. Augmentation techniques increase convective heat transfer by reducing the thermal resistance in a heat exchanger. Use of Heat transfer enhancement techniques lead to increase in heat transfer coefficient but at the cost of increase in pressure drop. So, while designing a heat exchanger using any of these techniques, analysis of heat transfer rate \& pressure drop has to be done. Apart from this, issues like long term performance \& detailed economic analysis of heat exchanger has to be studied. To achieve high heat transfer rate in an existing or new heat exchanger while taking care of the increased pumping power, several techniques have been proposed in recent years and are discussed in the following sections.

Several researchers discussed performance of different types of Techniques for Enhancement of heat in heat exchanger.

Saha and Dutta [1] investigated on circular tube with different configurations of inserted tapes of short length, full length smoothly varying pitch \& regular spaced twisted tapes for water as working fluid. They observed twisted tape is effective in laminar flow. Short length tape requires small amount of pumping power.

Saha and Bhunia [2] experimented in circular tube inserted with twisted tape with Servo therm oil as a working fluid; they found uniform pitch performs better than gradually decreasing pitch.

Ray and Date [3] numerically investigated on square ducts with water as fluid and proposed correlations for friction and $\mathrm{Nu}$. They observed high hydro thermal performance in square ducts rather than circular once.

Loknath and Misal [4] numerically investigated on plate heat exchanger and shell and tube heat exchanger inserted with twisted tape water \& lube oil as working fluids they concluded large value of overall heat transfer coefficient produced in water to water mode with oil to water mode.

A new method suggested by Sarma et al., [5] to predict heat transfer coefficients in circular tubes inserted with twisted tapes. They have modified eddy diffusivity expression given by van Driest to apply the same for internal flows in a tube with twisted tapes in laminar regime.

Liao and Xin [8] experimented on segmented twisted tape inserted tube with three dimensional extended surfaces with different working fluids like with ethylene glycol, turbine oil and found this configuration increases average Stanton number upto 5.8 times compared with empty plain tube. 
Sarma et al., [9] developed a new methodology to predict momentum and thermal diffusivities for turbulent flows in tubes. Their methodology has shown good agreement with Dittus and Boelter correlation and classical solution of Blasius wall friction coefficient.

Al-fahed and Chakroun [10] conducted experiments on single shell and tube heat exchanger with different twist ratio sand micro fin and found that low twist ratios resulting low pressure drop, tight fit enhances heat transfer.

Wang and Sunden [11] [worked on twisted tape in circular tube water as working fluid, their experiment results both inserts effective in enhancing heat transfer in laminar region compared with turbulent flow; twisted tape has poor overall efficiency if pressure drop is considered.

Saha and Chakraborty [12] investigated circular tube inserted with regularly spaced twisted tapes. They found large number of turns may yield improved thermo hydraulic performance compared with single turn.

\section{Numerical Simulation of Heat Exchanger}

\subsection{Numerical Simulation with Modeling}

A tube in shell heat exchanger is designed with a fluid inlet at one end and exit at another end of the shell. As shell side fluid flows inside annulus, the second fluid is made to flow within tube. Both the fluids were made to run under fully developed laminar conditions by providing calming sections. The temperatures of fluid at various sections of pipe were measured with the help of thermocouples and digital temperature indicator. The fluid flow in the test section is regulated with valves and is measured by using flow meters. The pressure drop across the test section for shell side and tube side fluids were measured by inserting micro-manometers across various pressure taps. The experimental data is compared with the results of similar analysis done in CFD package like ANSYS Fluent. The deviation of the results was found to be within $3.5 \%$ and results were also compared with standard shell and tube heat exchanger correlations for a smooth tube without inserts. Thereby the legitimacy of simulations is verified and simulations with further modifications in model were carried out.

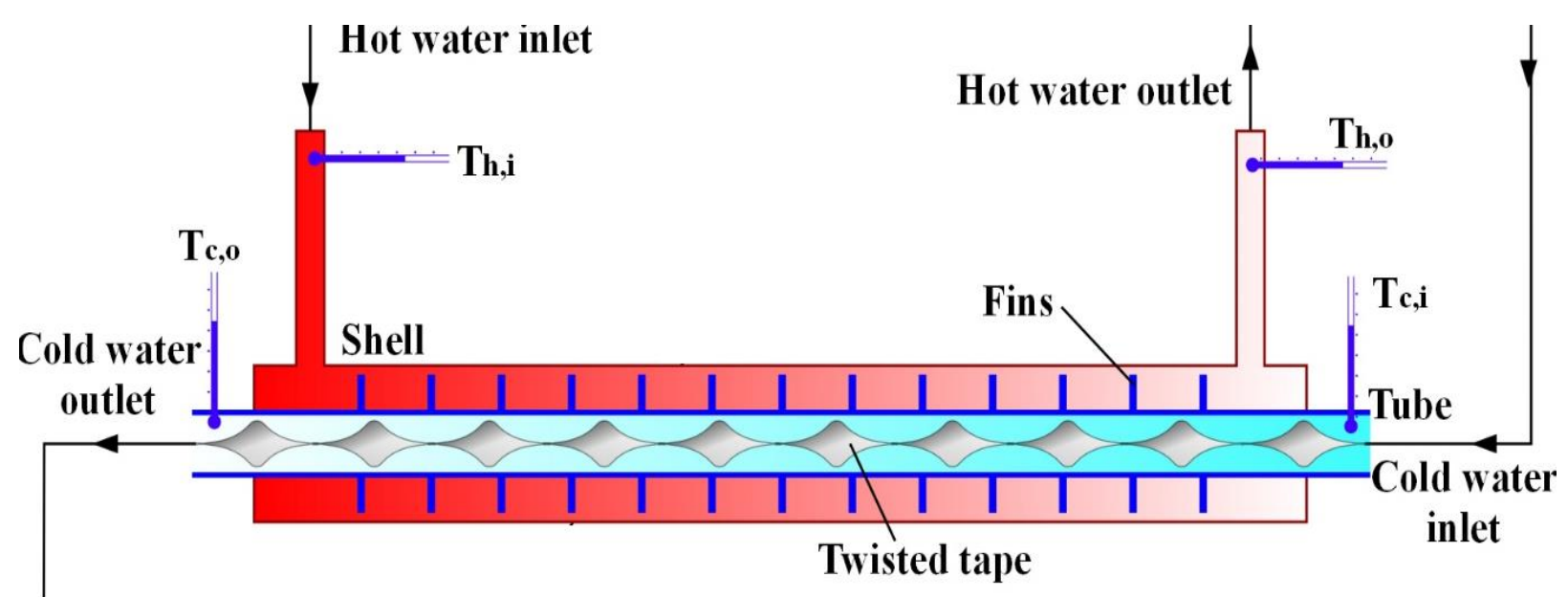

Figure 2: Cross-Sectional CFD Model of Finned Twisted Tape Heat Exchanger 


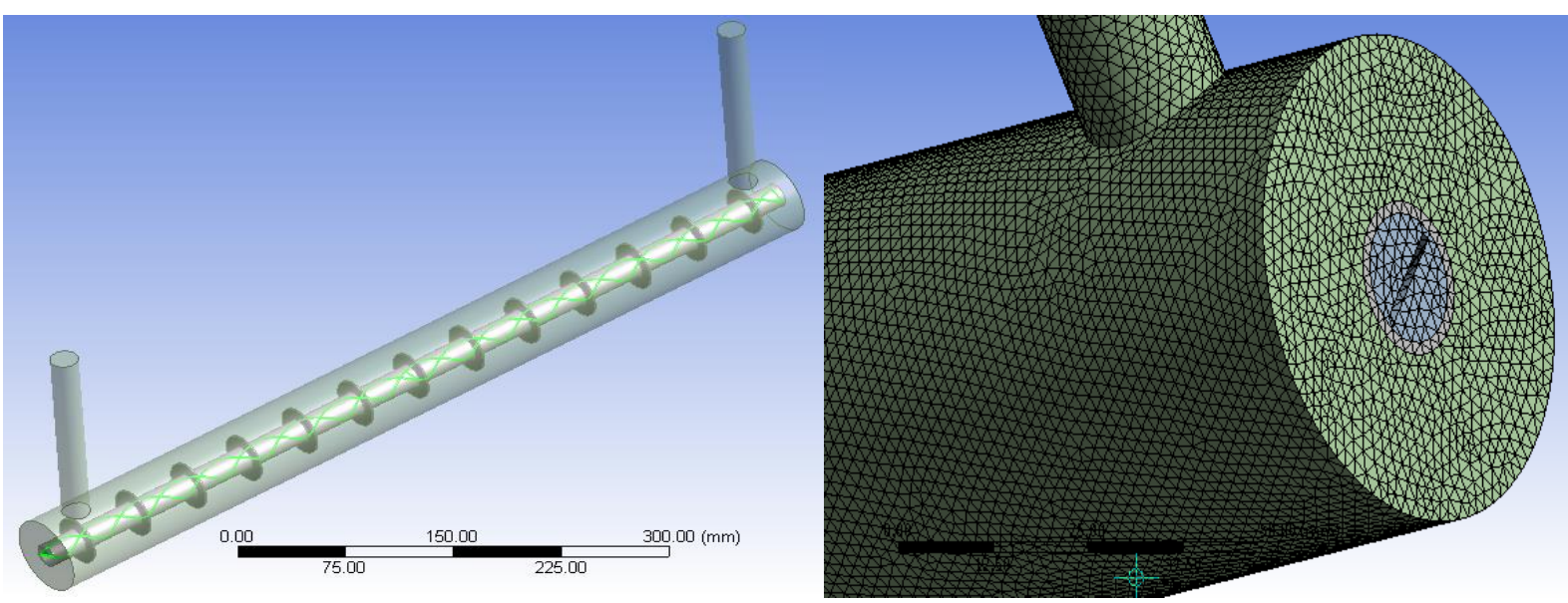

Figure 3: Geometric model and Discretisation

In this setup consists of the small tube of diameter $16 \mathrm{~mm}$ in a shell of diameter $60 \mathrm{~mm}$.

The tube consists of the 13 circumferential circular fins of diameter $38 \mathrm{~mm}$ with an offset distance of $50 \mathrm{~mm}$ between the fins.

Thickness of the fin is $1 \mathrm{~mm}$, tube thickness is $1.5 \mathrm{~mm}$.tube inner diameter is $16 \mathrm{~mm}$ and outer diameter $19 \mathrm{~mm}$.material of the tube is copper.

Twist tape inserted inside of the tube with twist ratio ranging from 4 to 5 .

\section{Analysis of the Problem}

In this section a few important terms and formulae commonly used in heat transfer augmentation work were presented.

\subsection{List of Formulas Used}

Thermo-hydraulic performance: For a particular Reynolds number, the thermo-hydraulic performance of an insert is said to be good if the heat transfer coefficient increases significantly with a minimum increase in friction factor. Thermo-hydraulic performance estimation is generally used to compare the performance of different inserts such as twisted tape, wire coil, etc., under a particular fluid flow condition.

Overall enhancement ratio: The overall enhancement ratio (or Thermal performance factor) is defined as the ratio of the heat transfer enhancement ratio to the friction factor ratio. This parameter is also used to compare different passive techniques and enables a comparison of two different methods for the same pressure drop. The overall enhancement ratio is defined as

$$
\eta=\frac{\left(N u / N u_{o}\right)}{\left(f / f_{o}\right)^{1 / 3}}
$$


Where, $\mathrm{Nu}, \mathrm{f}, \mathrm{Nu}_{0}$ and $\mathrm{f}_{0}$ are the Nusselt numbers and friction factors for a duct configuration with and without inserts respectively. The friction factor is a measure of head loss or pumping power.

Nusselt number: The Nusselt number is a measure of the convective heat transfer occurring at the surface and is defined as $h d / k$, where $h$ is the convective heat transfer coefficient, $d$ is the diameter of the tube and $\mathrm{k}$ is the thermal conductivity.

Pitch: Pitch is defined as the distance between two points that are on the same plane, measured parallel to the axis of a twisted tape.

Twist ratio (y): The twist ratio is defined as the ratio of pitch to inside diameter of the tube

$$
y=\frac{H}{d_{H}}
$$

Where $\mathrm{H}$ is the twist pitch length and $d_{H}$ is the hydraulic mean diameter

\section{Energy balance equation}

$$
Q_{\text {water }}=Q_{\text {convention }}
$$

The heat gain by the water can be written as,

$$
Q_{\text {water }}=m c_{p}\left(T_{\text {out }}-T_{\text {in }}\right)
$$

Where, $m$ is the mass flow rate water, and $c_{P}$ is the specific heat of the water

The convective heat transfer from the surface of the tube may be written as,

$$
Q_{\text {convention }}=h A_{s}\left(T_{s}-T_{b}\right)
$$

Where $A_{s}$ the surface area of the square duct is, $T_{s}$ is the average surface temperature and $T_{b}$ is the average of the inlet and outlet temperatures of water.

$$
A_{s}=\pi d_{H} L
$$

Where $d_{H}$ is the hydraulic mean diameter of the tube and $L$ is the length of the test tube. Average Nusselt number is calculated as: 


$$
N u=\frac{h D}{k}
$$

Where $k$ is the thermal conductivity of the water at temperature $T_{b}$ The Reynolds number is calculated as,

$$
\operatorname{Re}=\frac{U D}{v}
$$

Where $U$ is the average velocity of the fluid across the section and $v$ is the kinematic viscosity of the fluid at temperature $T_{b}$.

In the fully developed flow, the friction factor $(f)$ is determined by measuring pressure drops across the test tube length as:

$$
f=\frac{2 \Delta P}{L \rho U^{2} D}
$$

Where $\Delta P$ is the pressure drop between the inlet and outlet of the test section and $\rho$ is the mass density of fluid at temperature $T_{b}$. The mean velocity of fluid $(U)$ is calculated from the mass flow rate of the water as shown below:

$$
T_{b}=\left(T_{\text {in }}+T_{\text {out }}\right) / 2
$$

All the thermo-physical properties of the water are calculated at the bulk mean temperature of the fluid $\left(T_{b}\right)$.Based on thermal performance factor, we predicated the best design of the twist tape insert inside a heat exchanger.

\section{Results and Discussions}

\subsection{Velocity Contours and Temperature Profiles}

The performance of a heat exchanger can be understood certainly by observing the Velocity contours, temperature profiles and other parameters like trend of Nusselt number $(\mathrm{Nu})$, hydraulic performance factor. In this study, the velocity contours within the tube and around the tube (within shell) were observed at various Reynolds numbers. And insert of twist tape interrupts the development of boundary layer of the fluid flow near the wall surface hence this increases fluid temperature in radial direction with large contact surface area finally the heat transfer rate increases. The thickness of the thermal boundary layer decides the amount of the diffusion heat transfer from wall to fluid. At lower twist ratio, the thickness of thermal boundary layer is small, causing a very small amount of diffusion heat transfer. Therefore, the overall heat transfer is mainly because of the convective currents generated by the transverse (radial) velocity. And the 
major changes in velocity contours are occurring near the tape that contribute to the flow variation at the core and promote heat transfer enhancement.

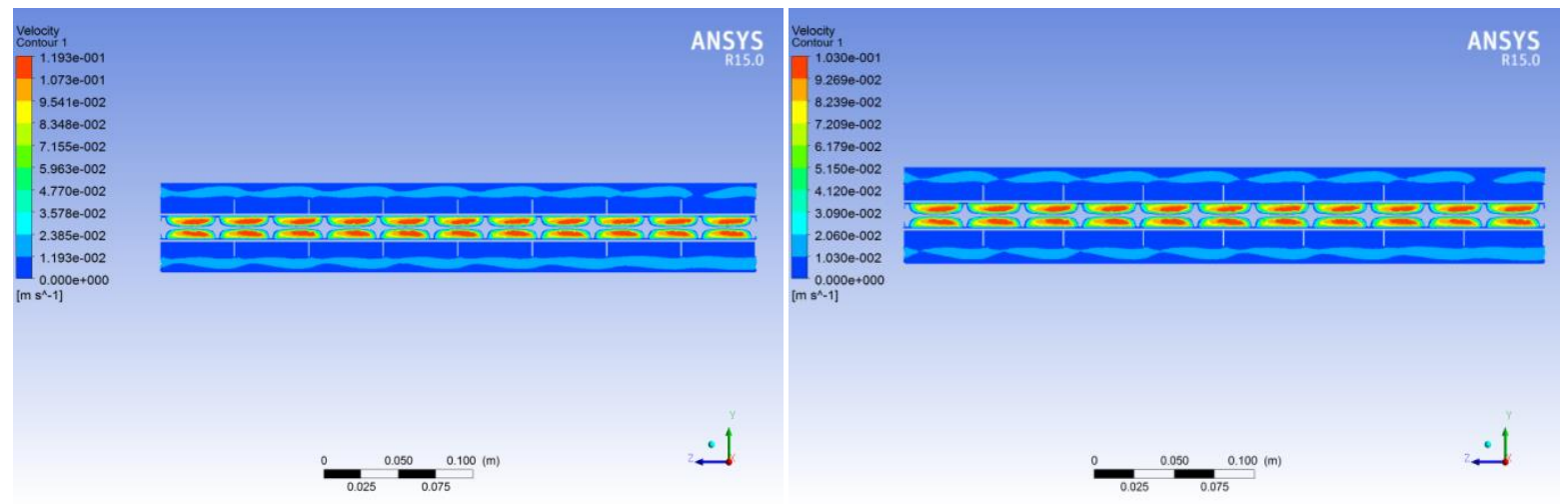

Figure 4: Velocity Profile

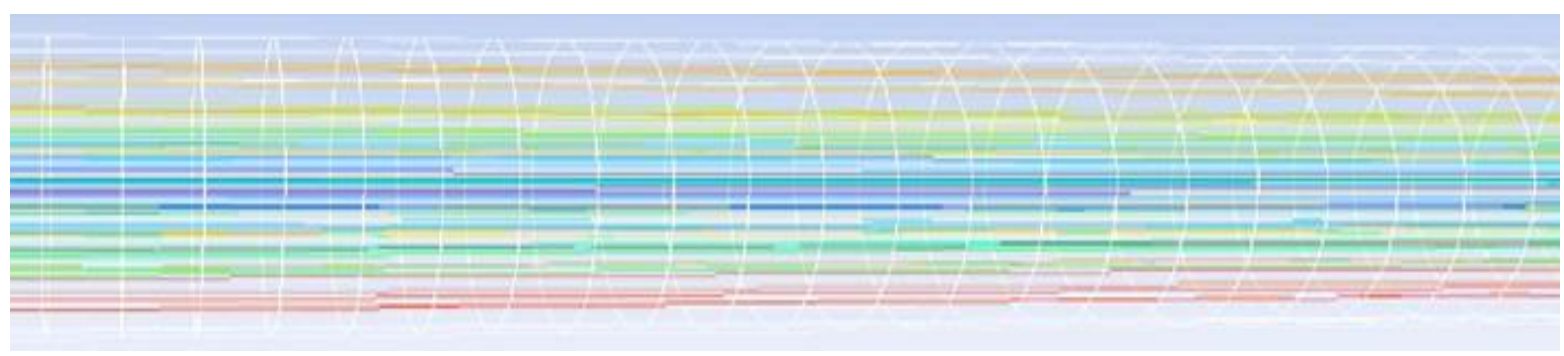

Figure 5: Path line in plain tube: Re-1500

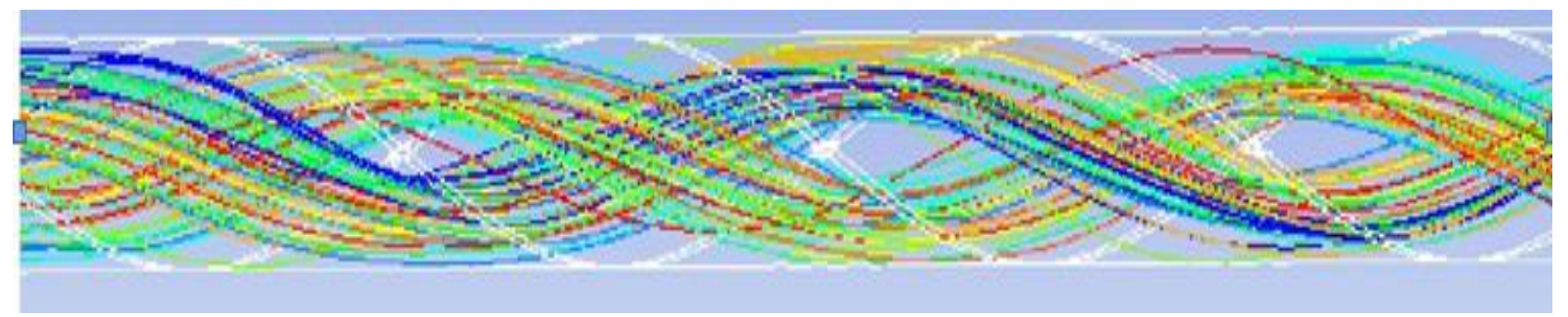

Figure 6: Velocity and path line along the twist ratio 4 and at $\mathrm{Re}-1500$

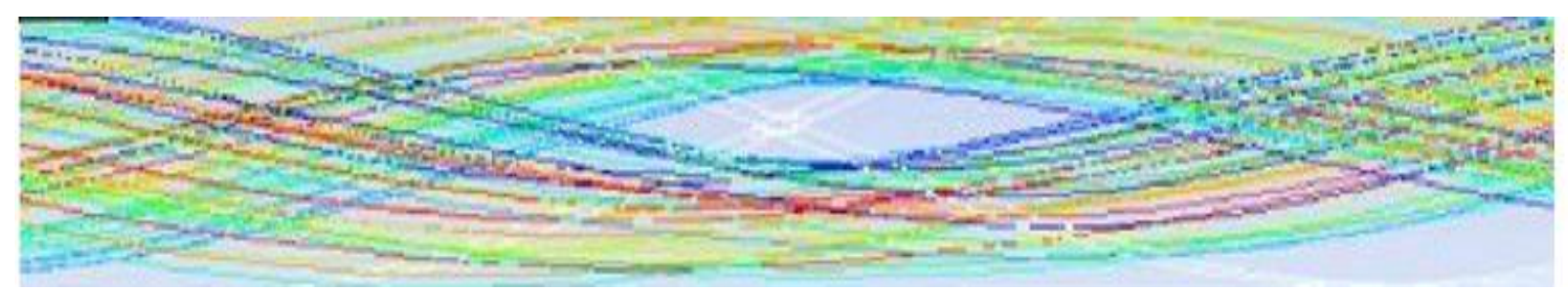

Figure 7: Velocity and path line along the twist ratio 5 and at Re-1500

It is observed from the velocity patterns that the flow becomes studier with the increase in Reynolds number in accordance with the predictions. With the sturdier velocity patterns, the temperature profiles were also enhance at higher Reynolds numbers as indicated by the temperature contours at various Reynolds number. 


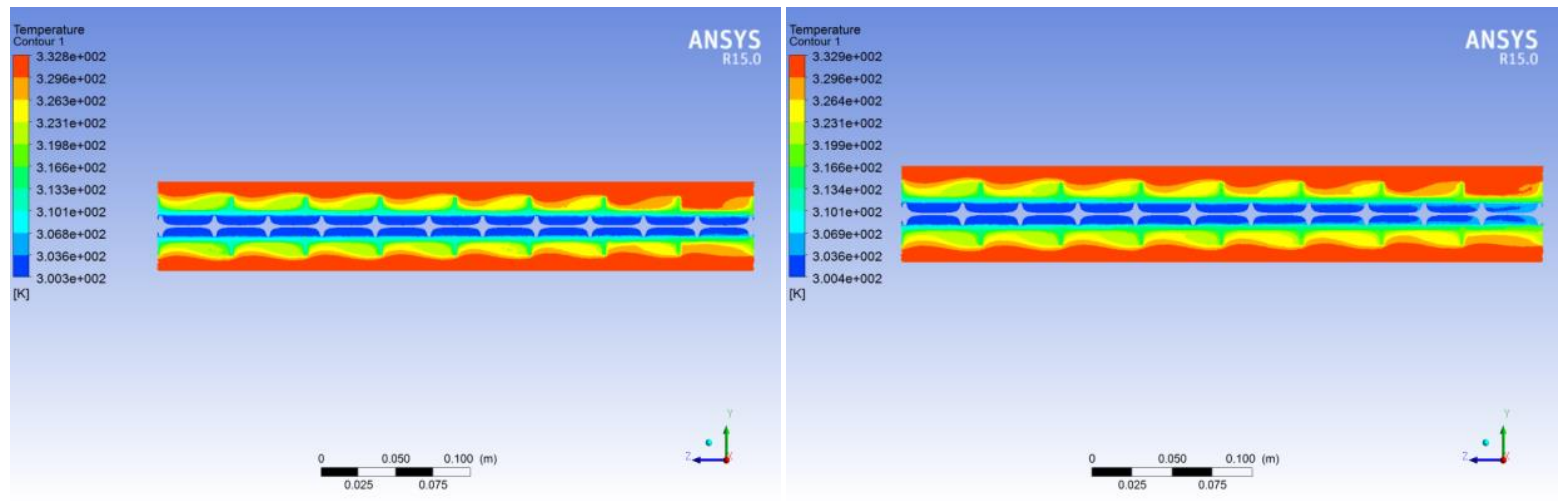

Figure 8: Temperature contours

The flow in heat exchanger without twisted tape is considered and the values of Nusselt number, shear stress were estimated at various Reynolds numbers .In following runs, similar flow is considered within heat exchanger with twisted tape of different twist ratios.

\section{Shear stress results:}

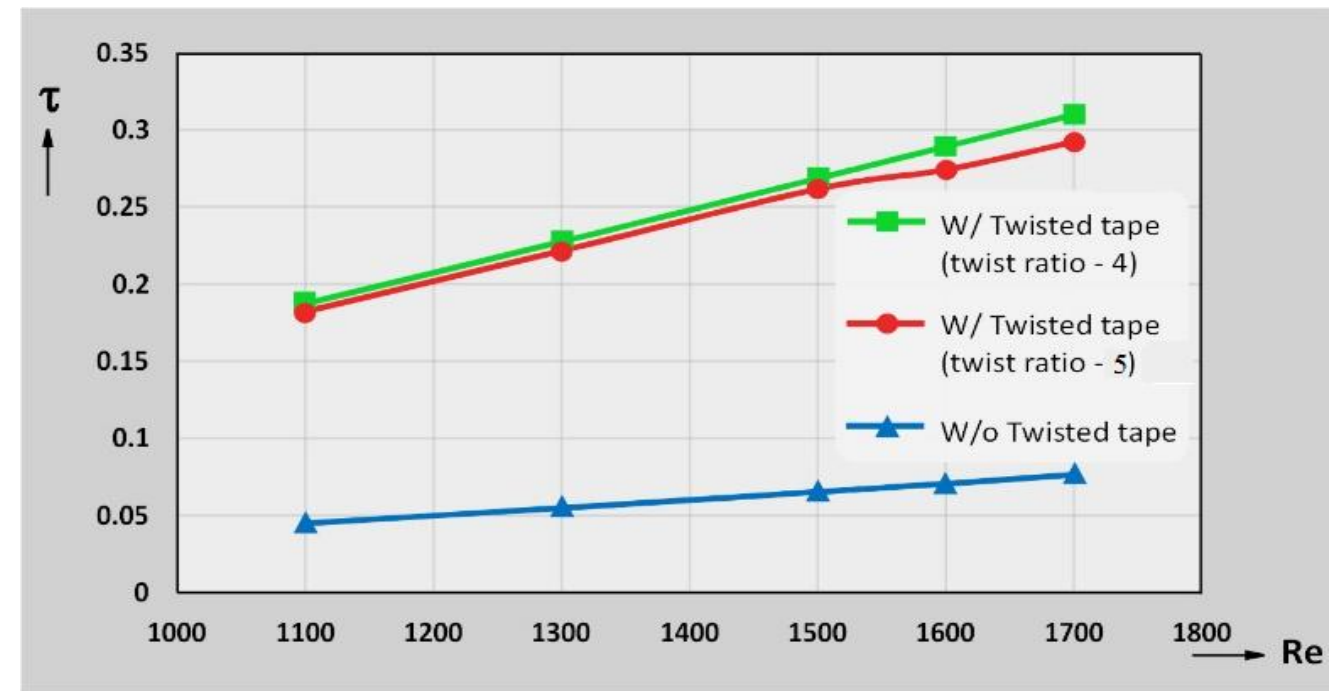

Figure 9: Graph between Reynolds Number (Re) vs. shear stress $(\tau)$

Above graph indicates the flow resistance in heat exchanger in terms of shear stress over a range of Reynolds numbers. Heat exchanger without twisted tape has less shear stress and indicates free flow of fluid within. However, adding twisted tapes of various twist ratios increased the shear stress values significantly and thereby demanding more pumping efforts for the flow of fluid in both tube and shell side And also friction factor decreases with increases of Reynolds number for different twist ratio. From the figure it can be seen that friction factor for the tube fitted with twist tape are significantly higher than plane tube for a given Reynolds number because reducing of swirl flow. 


\section{Heat Transfer results:}

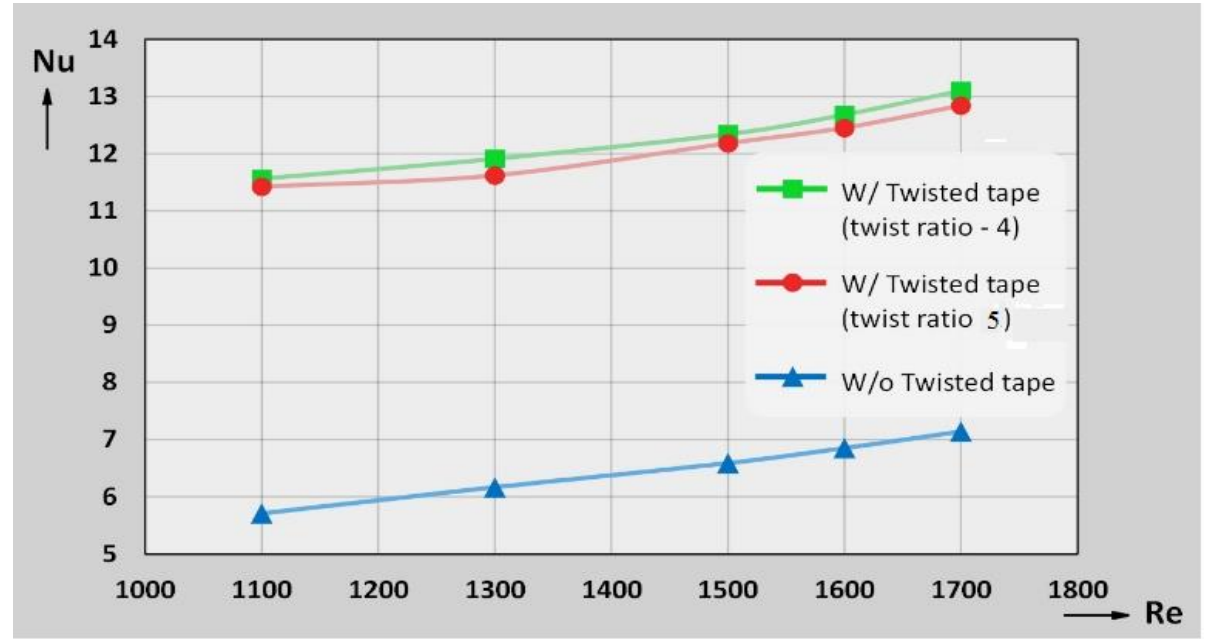

Figure 10: Graph between Reynolds Number (Re) vs. Nusselt number (Nu)

The comparison of Nusselt numbers for a range of Reynolds numbers corresponding to different twisted tape configurations is indicated in the above graph.

It is observed from the graph that heat exchanger with twisted tape insert performs well in terms of heat transfer aspects when compared to heat exchanger without twisted tape. However, increasing the twist ratio gave insignificant adverse effect in heat transfer augmentation

\section{Friction Factor Results:}

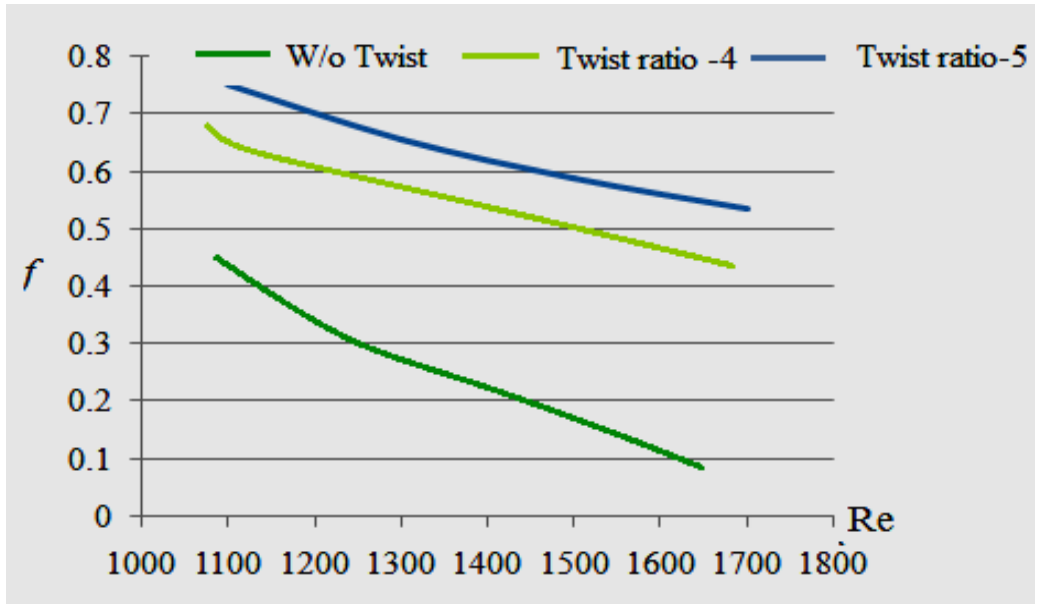

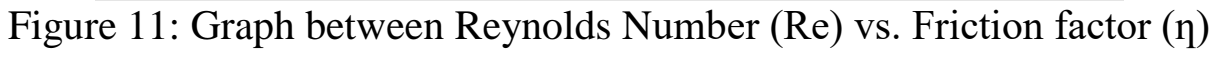

Variation of friction factor with Reynolds number in the tube fitted with twist tape and the plain tube are depicted in friction factor graph.

It shows that friction factor continuously decreases with Reynolds number and friction factor for lowest twist ratio $(y=4)$ is significantly more than that of higher twist ratio $(y=5)$ due to stronger 
swirl flow in tube over range studied the mean friction factor for the twist tube in heat exchanger with twist ratio $(\mathrm{y}=4$ and 5$)$ are higher than that of plain tube.

It shows that twist tube inserts in a heat exchanger yields higher pressure drops compared with plain tube, because of additional disturbance increases the tangential contact between secondary flow and wall surface of the tube.

Friction factor increases with decrease in twist ratio due to increases in swirl flow created with decreasing twist ratio.

\section{Thermal hydraulic Performance factor:}

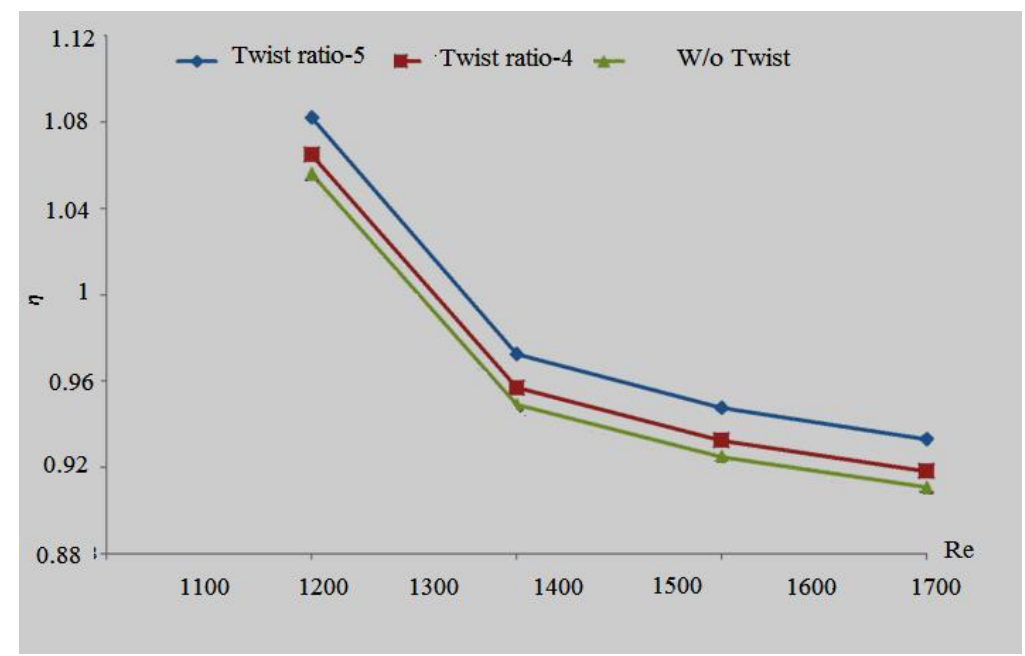

Figure 12: Graph between Reynolds Number (Re) vs. Thermal Performance factor ( $\eta$ )

Thermal Performance factor ( $\eta$ ) is the ultimate parameter used for evaluating the use of the twisted tape, simulation results. The factor is obtained by considering the effect of heat enhancement and the increase of pressure drop, consideration is based on the same pumping power consumption for tubes with and without a twisted tape insert. The variation of thermal performance factor with Reynolds number of the twist ratios ( $y=4,5$, W/o Twist) is shown in graph. Thermal performance factor increases with increasing Reynolds number in laminar region, decrease with increasing in Reynolds number in turbulent region.

\section{Conclusions}

The following conclusions are outlined by considering flow for water in circumferential finned twisted tape heat exchanger

1) From the velocity and temperature contours it is concluded that insertion of twisted tapes in finned tube heat exchanger interrupts the development of boundary layer of the fluid flow near the wall surface hence this increases fluid temperature in radial direction with large contact surface area finally the heat transfer rate increases.

2) From the Shear stress graph, it is concluded that, heat exchanger with plain tube has less shear stress and indicates free flow of fluid in the finned tube heat exchanger. However, adding twisted tapes of various twist ratios increased the shear stress values significantly 
and thereby demanding more pumping efforts for the flow of fluid in both tube and shell side. It is observed that shear stress increases $81.21 \%$ with twist ratio of 5 in finned tube heat exchanger compare with plain tube.

3) From the heat transfer results, heat exchanger with twisted tape insert performs well in terms of heat transfer aspects when compared to plain tube. However, increasing the twist ratio gave insignificant adverse effect in heat transfer increment at the ratio $88.88 \%$ compare with plain tube.

4) It is also observed that friction factor increases considerable limit for tubes with and without a twisted tape insert is in the ratio of $30 \%$.

5) The thermal performance with twist ratio 4 and 5 shows the best results for enhancement of heat transfer and pressure drop, by consider the same pumping power consumption for tubes with and without twisted tape insert.

\section{Nomenclature}

D Tube diameter $[\mathrm{m}]$

F Friction factor

$\mathrm{H}$ Convection heat transfer coefficient [W/m2 K]

$\mathrm{K}$ Thermal conductivity [W/m K]

$\mathrm{L} \quad$ Length of the tube [m]

M Mass flow rate $[\mathrm{kg} / \mathrm{s}]$

$\mathrm{Nu} \quad$ Nusselt number

$\mathrm{P} \quad$ Pitch [mm]

$Q_{\text {net }}$ Heat transfer rate [W]

$\mathrm{R}_{\mathrm{e}} \quad$ Reynolds number

$\mathrm{T}_{\mathrm{b}} \quad$ Bulk mean temperature of fluid [K]

$\mathrm{T}_{\text {in }} \quad$ Inlet temperature of fluid [K]

$\mathrm{T}_{\text {out }} \quad$ Outlet temperature of fluid [K]

$\mathrm{T}_{\mathrm{s}} \quad$ Average surface temperature of tube $[\mathrm{K}]$

$\mathrm{U} \quad$ Mean velocity of fluid $[\mathrm{m} / \mathrm{s}]$

y Twist ratio

$\Delta \mathrm{p} \quad$ Pressure difference across tube [N/m2]

\section{Greek symbols}

f $\quad$ Friction factor

$\eta \quad$ Thermo-hydraulic performance factor

$\rho \quad$ Density of fluid $[\mathrm{kg} / \mathrm{m} 3]$

$\tau \quad$ Shear stress[N/m $\left.\mathrm{m}^{2}\right]$

$v \quad$ Kinematic viscosity of fluid $\left[\mathrm{m}^{2} / \mathrm{s}\right]$

\section{References}

[1] Saha, S. K. and Dutta, A. (2001), Thermo-hydraulic study of laminar swirl flow through a circular tube fitted with twisted tapes. Trans. ASME, J. Heat Transfer, Vol.123, pp. 417-421. 
[2] Saha, S. K. and Bhunia, K. (2000), Heat transfer and pressure drop characteristics of varying pitch twisted-tape-generated laminar smooth swirl flow. In Proceedings of 4th ISHMTASME Heat and Mass Transfer Conference, India, pp. 423-428.

[3] Ray, S. and Date, A. W.(2003), Friction and heat transfer characteristics of flow through square duct with twisted tape insert, Int. J. Heat and Mass Transfer, Vol. 46, pp.889-902.

[4] Loknath, M. S. and Misal, R. D. (2002), An experimental study on the performance of plate heat exchanger and an augmented shell and tube heat exchanger for different types of fluids for marine applications. In Proceedings of 5th ISHMT- ASME Heat and Mass Transfer Conference, India, pp. 863-868

[5] Sarma, P.K., Subramanyam, T., Kishore, P.S., Dharma Rao, V., Sadic Kakac., (2003) Laminar convective heat transfer with twisted tape inserts in a tube., International Journal of Thermal Sciences, Vol. 42, pp. 821-828.

[6] Saha, S. K. Dutta, A. and Dhal, S. K. (2001), Friction and heat transfer characteristics of laminar swirl flow through a circular tube fitted with regularly spaced twisted-tape elements. Int. J. Heat and Mass Transfer, Vol. 44, pp. 4211-4223.

[7] Al-Fahed, S. Chamra, L. M. Chakroun, W. (1999), Pressure drop and heat transfer comparison for both micro-fin tube and twisted-tape inserts in laminar flow. Exp. Thermal and Fluid Sci., Vol.18, pp.323-333.

[8] Liao, Q. and Xin, M. D. (2000), Augmentation of convective heat transfer inside tubes with three-dimensional internal extended surfaces and twisted tape inserts. Chem. Eng. J.Vol.78, pp. 95-105.

[9] Sarma, P.K., Chada, K., Rao, V.D., Kishore, P.S., Subrahmanyam, T., Bergles, A.E., Evaluation of momentum and thermal eddy diffusivities for turbulent flow in tubes. International Journal of Heat and Mass Transfer 53 (5), 1237-1242

[10] Al-Fahed, S. and Chakroun, W. (1996), Effect of tube tape clearance on heat transfer for fully developed turbulent flow in a horizontal isothermal tube. Int. J. Heat and Fluid Flow, Vol.17, pp. 173-178.

[11] Wang, L. and Sunden, B. (2002), Performance comparison of some tube inserts. Int. Commun. Heat Transfer, Vol. 29, pp.45-56.

[12] Saha, S. K. and Chakraborty, D. (1997), Heat transfer and pressure drop characteristics of laminar flow through a circular tube fitted with regularly spaced twisted tape elements with multiple twists. In Proceedings of 3rd ISHMT-ASME Heat and Mass Transfer Conference, India, pp. 313-318.

[13] BrahmaNaidu, P.S., (2017) Performance evaluation of circumferential finned twisted tape heat exchanger. M. Tech Thesis, Andhra University., Visakhapatnam.

*Corresponding author.

E-mail address: psbn.301@ gmail.com 